\title{
ENGLISH
}

УДК 617.7-007.681-089

DOI: $10.25700 / 2078-4104-2021-20-2-51-56$

\section{Composite drainage in glaucoma surgery}

BotABEKova T.K., Dr. Sci. (Med.), Professor, corresponding member of the Kazakhstan

Academy of Sciences, Head of the Department of Ophthalmology';

ERICHEV V.P., Dr. Sci. (Med.), Professor, Head of the Glaucoma Department²;

Aldasheva N.A., Dr. Sci. (Med.), Acting Director ${ }^{3}$;

Bulgakova A.A., Cand. Sci. (Med.), Senior Lecturer ${ }^{3}$;

HACHATRYAN G.K., Cand. Sci. (Med.), Junior Researcher at the Glaucoma Department².

${ }^{1}$ Kazakh-Russian Medical University, Department of Ophthalmology, 71 Torekulova St., Almaty, Kazakhstan, 050004;

${ }^{2}$ Research Institute of Eye Diseases, 11A Rossolimo St., Moscow, Russian Federation, 119021;

${ }^{3}$ Kazakhstan Scientific Research Institute of Eye Diseases, 95A Tole bi St., Almaty, Kazakhstan, 050012.

Conflicts of Interest and Source of Funding: none declared.

For citations: Botabekova T.K., Erichev V.P., Aldasheva N.A., Bulgakova A.A., Hachatryan G.K.

Composite drainage in glaucoma surgery. Natsional'nyi zhurnal glaukoma. 2021; 20(2):51-56.

\section{Abstract}

PURPOSE. To assess the hypotensive effectiveness, frequency and nature of intra- and postoperative complications in patients with various clinical manifestations of refractory glaucoma.

MATERIALS AND METHODS. The study included $196 \mathrm{pa}-$ tients (196 eyes) with various forms, stages and clinical manifestations of glaucoma. There were 142 patients with primary glaucoma, among them 120 with open-angle glaucoma and 22 with angle-closure glaucoma. Among the patients with primary glaucoma, 85 had pseudophakia (77 with openangle and 8 with angle-closure forms); 57 had a native lens (43 with open-angle and 14 with angle-closure forms of the disease). Secondary glaucoma was presented mainly by patients with neovascular (21) and postuveal (16) glaucoma. The intraocular pressure (IOP) level in the group as a whole ranged from 16 to $50 \mathrm{~mm} \mathrm{Hg}$ (on average $30.1 \pm 2.6 \mathrm{~mm} \mathrm{Hg}$ ). In all presented cases of surgical intervention, the Glautex drainage was used, which is a bioresorbable composite biomaterial based on polylactic acid (polylactide) and polyethylene glycol (manufactured by "HiBiTech", Russia). Standard methods of patient examination were used.

RESULTS. In patients with POAG, the IOP averaged 13.7 $4.7 \mathrm{~mm} \mathrm{Hg}$ one week after surgery and $16.1 \pm 3 \mathrm{~mm} \mathrm{Hg} 12$ months after surgery. The absolute success of the operation was noted in 71 patients with POAG (59.2\%); the relative hypo- tensive effect - in $85.8 \%$. In primary angle-closure glaucoma, the same indicators were 47.6 and $61.1 \%$, respectively. In the group of patients with neovascular and postuveal glaucoma, the hypotensive effect was as expected lower and amounted to 42.8 and $50.0 \%$, respectively. The restart of therapy at different periods of observation was done in $78.3 \%$. Complications, their frequency and nature, noted by us in the operated patients, could be attributed to those typical for fistulizing operations in refractory glaucoma. The most common complication was ciliochoroidal detachment, which was seen in all groups, but percentage-wise was more common in patients with PACG, neovascular and postuveal glaucoma.

CONCLUSION. Composite drainage based on polylactic acid (polylactide) and polyethylene glycol (glautex) is an effective and safe solution to the issue of surgical treatment of glaucoma. The antihypertensive effectiveness of the Glautex drainage implant depends on the severity of the glaucomatous process and the timeliness of the surgical intervention. The frequency and nature of complications depends on the degree of refractoriness of glaucoma, initial clinical characteristics of the process, and patients' multimorbidity.

KEYWORDS: glaucoma, drainage, intraocular pressure, surgical treatment.

For contacts:

Erichev Valeriy Petrovich, e-mail: v.erichev@yandex.ru 


\section{Introduction}

Surgical treatment of glaucoma is justifiably considered the most reliable method of achieving safe levels of intraocular pressure (IOP) as a principal way of preserving the visual function [1-3]. There are various filtering and fistulizing surgeries with numerous modifications, which only shows that with overall clinical polymorphism of glaucoma it is unlikely any one method can be universally effective and safe.

In the nineties, a new term "refractory glaucoma" was introduced in Russian scientific literature; it comprises different clinical forms of glaucoma with history of unsuccessful therapy [4].

The severity of clinical course of refractory glaucoma prompted a classification by the degree of refractoriness $[5,6]$. Three degrees are recognized: I degree advanced primary open-angle glaucoma (POAG), pseudoexfoliation and pigmentary glaucoma, glaucoma in individuals younger than 50 years old, unsuccessful surgery on the paired eye; II degree - previously operated POAG, pseudophakic glaucoma, juvenile glaucoma; III degree - primary or secondary glaucoma operated several times, neovascular glaucoma, uveitic glaucoma with neovascularization.

The variability of refractory glaucoma forms determines the search of new treatment methods utilizing new techniques primarily aimed at preventing cicatrization in the surgery site. One of such techniques is drainage surgery.

According to many existing protocols, official indication for drainage surgery is a history of unsuccessful trabeculectomy with antimetabolite therapy. The actual clinical practice, however, has demonstrated the need for expanding these indications - one of the reasons being decreased effectiveness of surgical interventions due to late discontinuation of tropical therapy and toxic effects of preservatives on ocular surface tissues [7].

The use of drainage devices and products has become the key approach to prolongation of the hypotensive effect of glaucoma surgeries [8-11].

All drainage devices can be classified by the material of which they are manufactured, and by their technical features. The latter, in turn, divides them into two big groups:

- devices promoting active outflow of aqueous humor from the anterior chamber: drainages Molteno, Krupin, Schocket, Baerveldt, Ahmet, Ex-PRESS shunt;

- devices preventing excessive scarring (sclero-scleral or sclero-conjunctival) and enabling passive aqueous outflow from the anterior chamber: Xenoplast, iGen, HealaFlow, Glautex etc.

Depending on the source material, the drainage devices can be: autotransplants (from patient's own tissues), allotransplants (from donor tissue), xenotransplants (from animal tissue), explantodrainages (from polymers and metals). Auto- and allotransplants have high biological compatibility with human ocular tissues, do not cause significant inflammatory reactions, and so have been used extensively [12-16]. However, since they biodegrade fast, the long-term antihypertensive effect could not be achieved with them.

The use of various drainages was suggested in order to prevent excessive scarring in the surgery site, which is one of the main causes of unsuccessful outcomes of anti-glaucoma operations. S.Yu. Anisimova and S.I. Anisimov proposed a xenotissue implant made of raw collagen with porous structure. Clinical trials and years of practical use have shown it to be highly effective and safe [17-19].

The biodegradable collagen drainage iGen is a porous glycosaminoglycan matrix consisting of collagen and chondroitin-6-sulfate; it was suggested as a prevention measure against conjunctiva-sclera adhesion and showed certain effectiveness, but did not find widespread adoption [20-23].

Among other options is Glautex (HiBiTech, Russia) - a Russian-manufactured drainage of original design. This composite drainage made from polylactic acid (polylactide, PLA) and polyethylene glycol (PEG) comes as a range of models with different shapes, sizes, as well as nanoparticle sputtering $(\mathrm{Ag}, \mathrm{Au})$. Bioresorption properties of this drainage allow its full reabsorption in 4-8 months while leaving behind a sustained area for aqueous humor outflow, which ensures stable antihypertensive effect [24]. It has seen widespread adoption in Russia and the neighboring countries. In this respect, we believe it will be useful to summarize and describe the experience with the Glautex drainage in patients with different clinical presentations of glaucoma.

The purpose of this study is to assess the antihypertensive effectiveness, incidence and nature of intraand postoperative complications in patients with various clinical manifestations of refractory glaucoma.

\section{Materials and methods}

The study was conducted at the Kazakh Research Institute of Eye Disease (Almaty) and the Research Institute of Eye Diseases (Moscow) using similar protocols.

The data obtained from the two study sites were consolidated and then processed with classical methods of statistical evaluation. Standard deviation was calculated for all statistical values. Where necessary, frequency distribution was evaluated. Student's t-test was used for values distributed according to the normal distribution law. Statistical processing and data visualization were done using the following software: PSPP for Linux (psppire 0.7.9, GNU General Public License), MS Excel 2003 (Microsoft, USA), CorelDraw (Corel, USA).

Surgical intervention in all presented cases involved the Glautex drainage - biodegradable composite biomaterial based on PLA and PEG (manufactured by HiBitech LLC, Russia). It has rectangular collar-like shape (closed ring) of $2.5 \times 5.5 \mathrm{~mm}$ dimensions in collapsed form, $150 \mu \mathrm{m}$ in thickness, with pore diameter 
Table 1. Technical characteristics of the Glautex drainage

\begin{tabular}{|c|c|c|c|}
\hline \multirow{2}{*}{ Parameter } & \multicolumn{3}{|c|}{ Model } \\
\hline & DDA & TDA & SDA \\
\hline \multirow[b]{2}{*}{ Material } & Composite material bc & n polylactic acid (polylact & and polyethylene glycol \\
\hline & $\begin{array}{l}\text { treated with plasmonic } \\
\text { nanosilver }\end{array}$ & $\begin{array}{c}\text { treated with plasmonic } \\
\text { nanosilver }\end{array}$ & $\begin{array}{c}\text { not treated with plasmonic } \\
\text { nanosilver }\end{array}$ \\
\hline Structure & porous & porous & porous, microfiber \\
\hline Time until resorption, months & $4-8$ & $4-8$ & $4-8$ \\
\hline Thickness, $\mathrm{mm}$ & 0,15 & 0,15 & 0,22 \\
\hline Width, $\mathrm{mm}$ & $2,0 \pm 0,2$ & $2,0 \pm 0,2$ & $2,0 \pm 0,2$ \\
\hline Length, $\mathrm{mm}$ & $5,2 \pm 0,2$ & $5,2 \pm 0,2$ & $5,0 \pm 0,2$ \\
\hline
\end{tabular}

of 5-30 $\mu \mathrm{m}$. Short time of reabsorption - 4-5 months on the average - is attributed to weaker links in its chemical structure. There are several different models that differ in material structure, affecting the product's thickness, as well as whether they've been treated with plasmonic Ag nanoparticles (Table 1). Besides that, there are differences in geometric configuration that let the surgeons inventively approach the implantation and account for possible non-typical situations (Fig. 1).

The study included 196 patients (91 men, 105 women; mean age $68.3 \pm 9.11$ years; 196 eyes) with different forms, stages and clinical presentations of glaucoma (Table 2). There were 142 patients with primary glaucoma, among them 120 with open-angle form and 22 with angle-closure form. Among patients with primary glaucoma, 85 were pseudophakic (77 with openangle and 8 with angle-closure forms); 57 had native lens (43 with open-angle and 14 with angle-closure forms).
Distribution of study patients with secondary glaucoma can be seen in Table 2 showing that neovascular and uveitic glaucoma accounted for the largest number of cases.

Group-wise IOP levels varied between 16 and $50 \mathrm{~mm} \mathrm{Hg}$ (mean IOP of $30.1 \pm 2.6 \mathrm{~mm} \mathrm{Hg}$ ). On the day before surgery, best efforts were made to reduce IOP. Patients with uveitic glaucoma were operated only with uveitis in stable remission, and their preoperative preparation was complemented with steroidal and non-steroidal drugs. Patients with neovascular glaucoma had an angiogenesis inhibitor administered intracamerally 3-4 days before surgery in order to prevent hemorrhagic complications; permission for that was granted by the local medical-biological ethical committee.

The core surgery was standard sinus trabeculectomy involving dissection of a quadrangular scleral flap. To prevent acute IOP elevation, anterior chamber paracentesis was performed in every case.
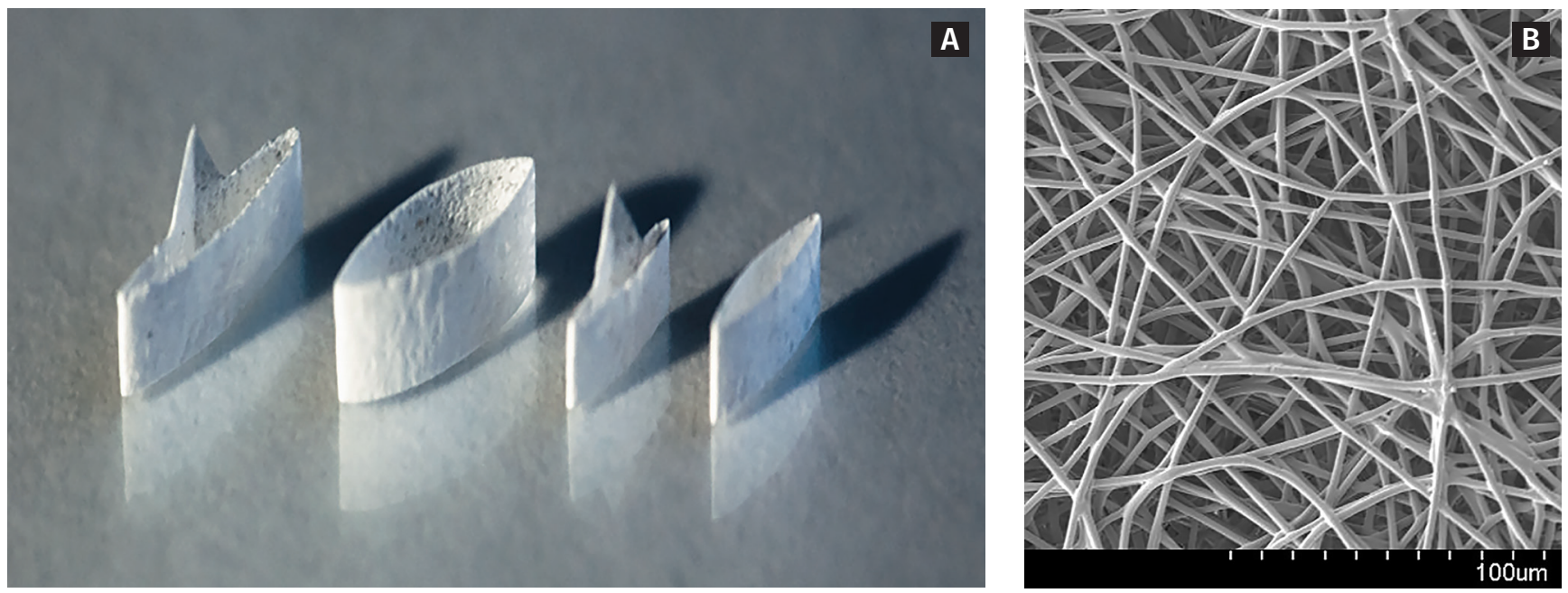

Fig. 1. The Glautex drainage: A — appearance; B — electron micrograph 
Table 2. Distribution of patients (eyes) by form and stage of glaucoma (general characteristics)

\begin{tabular}{|c|c|c|c|c|c|c|c|}
\hline \multirow{3}{*}{ Stage } & \multicolumn{6}{|c|}{ Distribution of glaucoma by etiology } & \multirow{3}{*}{ Total } \\
\hline & \multicolumn{2}{|c|}{ primary glaucoma } & \multicolumn{4}{|c|}{ secondary glaucoma } & \\
\hline & POAG & PACG & neovascular & postuveal & posttraumatic & other & \\
\hline 1 & 12 & - & - & - & - & - & 12 \\
\hline ॥ & 23 & 4 & 2 & - & 1 & 3 & 33 \\
\hline III & 79 & 18 & 19 & 16 & 2 & 11 & 145 \\
\hline IV & 6 & - & - & - & - & - & 6 \\
\hline Total & 120 & 22 & 21 & 16 & 3 & 14 & 196 \\
\hline
\end{tabular}

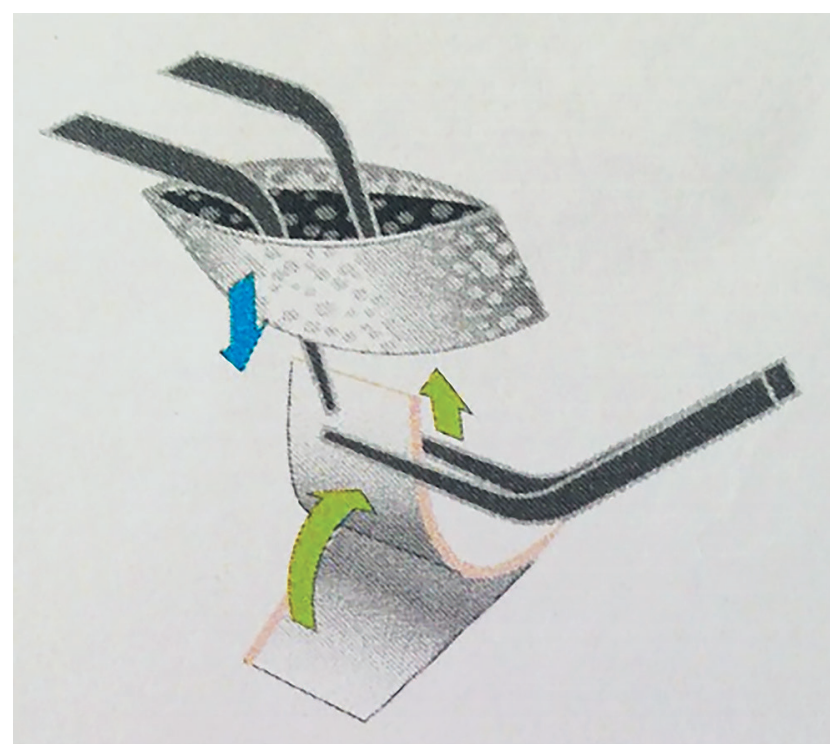

Fig. 2. Implantation scheme of the Glautex drainage

The collar-shaped drainage was put on the scleral flap (Fig. 2) during one of the final surgery stages (before scleral suturing). Then the scleral flap was fixated by two seams, and the conjunctiva was closed with continuous sutures. Two different drainage models were used in the surgery: DDA and TDA.

Monitoring of IOP in most of the operated patients was carried out on day 7 , then after $1,3,6$ and 18 months. The follow-up period lasted up to 18 months.

\section{Results and discussion}

In POAG patients, IOP after 1 week was on average $13.7 \pm 4.7 \mathrm{~mm} \mathrm{Hg}$. On day 30 after surgery, it increased by $2-3 \mathrm{~mm} \mathrm{Hg}$ and amounted to $15.3 \pm 5.1 \mathrm{~mm} \mathrm{Hg}$. In the following months, IOP fluctuations were within the norm, and after 12 months IOP was $16.1 \pm 3 \mathrm{~mm} \mathrm{Hg}$ (Fig. 3). Compared to baseline, IOP has decreased by $14-32 \mathrm{~mm} \mathrm{Hg}$ (on average by $21.5 \pm 3.6 \mathrm{~mm} \mathrm{Hg}$ ). The level of IOP reduction directly correlated with the initial (preoperative) IOP values.
Absolute success of surgery with Glautex drainage implantation was observed in $71(59.2 \%)$ patients with POAG. In $32(26.6 \%)$ cases, hypotensive therapy (monotherapy) was needed to achieve sustained IOP normalization. Thus, the relative hypotensive effect amounted to $85.8 \%$.

In cases when sustained IOP reduction could not be achieved, the failure was explained by glaucoma severity (advanced stage, initially high IOP, previously operated glaucoma). Hypotensive outcomes in phakic and pseudophakic eyes were comparable.

Patients with primary angle-closure glaucoma (PACG) exhibited lower levels of IOP reduction in the eyes with native lens compared to pseudophakic eyes. The most likely explanation for that is larger opening of the anterior chamber angle after lens removal and, subsequently, better accessibility of the drainage area for aqueous humor outflow. Absolute antihypertensive effectiveness amounted to $47.6 \%$; relative $-61.1 \%$.

In cases when IOP elevation was observed at different times, needling was performed in addition to topical therapy $(13.5 \%)$ in order to improve the antihypertensive effectiveness of the drainage surgery. The procedure was carried out in $49.1 \%$ of cases. However, in $8.6 \%$ of cases repeated surgery was still necessary.

The antihypertensive effect was predictably lower in the group of patients with neovascular and uveitic glaucoma amounting to 42.8 and 50\%, respectively. The therapy was restarted in $78.3 \%$ of cases at various times during the follow-up period. Treatment of choice mostly consisted of carbonic anhydrase inhibitors and agonists of alpha-2-adrenoceptors. Safe IOP levels were achieved in $57.1 \%$ of neovascular glaucoma cases and in $75.0 \%$ of uveitic glaucoma patients. Aseptic inflammation during the postoperative period was more pronounced in the latter group, which required additional steroidal and nonsteroidal anti-inflammatory drugs.

In silicon oil induced glaucoma, with one of the main causes of aqueous humor retention being blockade of the drainage area by oil microdeposits, the surgery targeted the inferior quadrant. The geometry and physical parameters of the Glautex drainage allowed 
Table 3. Evaluation of antihypertensive effectiveness in study groups (\%)

\begin{tabular}{ccccc}
\hline & \multicolumn{4}{c}{ Distribution of glaucoma by etiology } \\
\cline { 2 - 5 } $\begin{array}{c}\text { Antihypertensive } \\
\text { effectiveness }\end{array}$ & primary & neovascular & secondary \\
\cline { 2 - 5 } & POAG & PACG & 42,8 & 50,0 \\
Absolute & 59,2 & 47,6 & 57,1 & 75,0 \\
Relative & 85,8 & 61,1 & & postuveal \\
\hline
\end{tabular}

Table 4. Frequency and nature of postoperative complications in study groups (\%)

\begin{tabular}{|c|c|c|c|c|c|}
\hline \multirow{3}{*}{ Nature of complications } & \multicolumn{4}{|c|}{ Distribution of glaucoma by etiology } & \multirow{3}{*}{ Total } \\
\hline & \multicolumn{2}{|c|}{ primary } & \multicolumn{2}{|c|}{ secondary } & \\
\hline & POAG & PACG & neovascular & postuveal & \\
\hline CCD & 9,2 & 18,2 & 19,0 & 18,7 & 16,3 \\
\hline Hyphema & 3,3 & 4,6 & 14,3 & 6,2 & 7,1 \\
\hline Hypertension & 1,6 & 9,1 & 14,3 & 6,2 & 7,8 \\
\hline Aseptic anterior uveitis & - & - & 4,7 & 18,7 & 11,7 \\
\hline Refractory hypotension & 2,5 & - & - & 1,6 & 2,0 \\
\hline
\end{tabular}

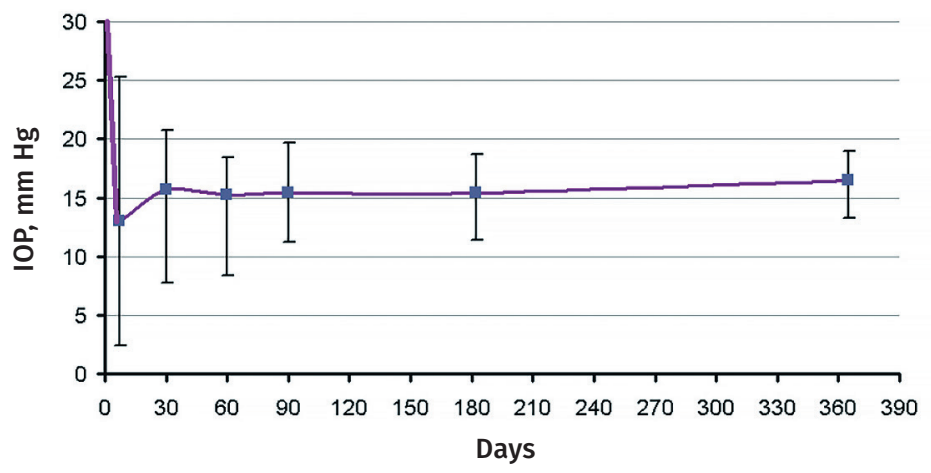

Fig. 3. Time course of IOP changes after Glautex drainage implantation

achieving good antihypertensive and aesthetic outcomes. All 6 patients showed decrease of IOP by an average of $14.7 \pm 2.5 \mathrm{~mm} \mathrm{Hg}$, and by the end of the follow-up it amounted to $18.3 \pm 1.9 \mathrm{~mm} \mathrm{Hg}$. Antihypertensive therapy for normalization of the IOP after repeated removal of the silicone oil, which caused IOP elevation of up to $26 \mathrm{~mm} \mathrm{Hg}$, was necessary only in one case.

Best hypotensive outcomes were observed in patients with pseudophakia, for whom Glautex drainage implantation was the initial surgery. In all of the 18 patients, mean IOP was $17.8 \pm 2.3 \mathrm{~mm} \mathrm{Hg}$ during the 12-months follow-up. It is mostly explained by the absence of additional factors such as cicatricial changes in the surgery site.
Table 3 shows the total antihypertensive effectiveness in the most common clinical situations. Absolute effectiveness means IOP normalization as outcome of the surgery, relative - with additional topical therapy.

Central visual acuity cannot serve as an objective criterion of the effectiveness of glaucoma surgery for obvious reasons. Instead, when applicable, assessment of the visual function was done using the full field 120 point screening test. The amount of points was noted to have increased by $10-32 \%$ depending on the severity of the glaucomatous damage, which we ultimately considered as the result of achieving safe IOP levels.

The complications, their incidence and nature that we observed in operated patients can be referred to as typical for fistulizing surgeries in refractory glaucoma. Table 4 shows summarized data for main groups of operated patients. Ciliochoroidal detachment (CCD) was the most frequent complication; it occurred in all groups, but percentage-wise it was more common in patients with PACG, neovascular and uveitic glaucoma. In cases with extended CCD and ineffective conservative therapy, sclerectomy was performed for evacuation of subscleral aqueous.

Despite the special preoperative preparation, hemorrhagic complications could not be avoided; they were more common in neovascular glaucoma. This is associated with the presence of anatomical-morphological substrate, as well as significant gradient between extraand intravasal pressure, which is critical for opening 
the eyeball. Presence of a hyphema required additional strenuous treatment, and in some cases it was the cause of postoperative ophthalmic hypertension.

Aseptic anterior postoperative uveitis we specified as such inflammation that required an increase in standard treatment. In all cases of uveitic secondary glaucoma, surgical intervention was performed in conditions of stable remission. A surgical trauma event leads to a release of significant amount of endogenous prostaglandins and leukotrienes providing conditions for the development of aseptic inflammation. Non-steroidal and steroidal anti-inflammatory therapy in the postoperative period was effective and led to expected outcomes. Only in one case of uveitic glaucoma with initially high IOP, there was pronounced and persistent hypotension with significant structural and functional changes in the central retinal zone, confirmed by optical coherence tomography.

Among all patients who were implanted with the Glautex drainage, only in $4(2.0 \%)$ it tore through the conjunctiva. It happened in patients with advanced glaucoma under long-term topical therapy containing preservatives, which naturally leads to structural changes in the tissues of anterior ocular surface [24]. Another possible cause may have been inappropriate storage conditions of the drainage implants.

\section{References}

1. Astakhov S.Yu., Astakhov Yu.S., Bresel Yu.A. Refractory glaucoma surgery: what can we offer? Glaucoma: theories, trends, technologies HRT-club Russia: IV International conference: Sat. articles. Moscow; 2006: 24-29. (In Russ.)

2. Astakhov Yu.S., Egorov E.A., Bresel Yu.A. Surgical treatment of "refractory" glaucoma. Clin. ophthalmology. 2006; 2(1):25-27. (In Russ.)

3. Bessmertny A.M. Risk factors for excessive scarring in patients with primary open-angle glaucoma. J Glaucoma. 2005; 3:34-37. (In Russ.)

4. Erichev V.P. Surgical and ultrasound treatment of the main forms of refractory glaucoma: Author's abstract dis. ... Dr. of Medical Sciences. Moscow; 1997. (In Russ.)

5. Bessmertny A.M. System of differential surgical treatment of refractory glaucoma: Dis. ... Dr. of Medical Sciences. Moscow; 2006: 180-196. (In Russ.)

6. Erichev V.P. Refractory glaucoma: treatment features. Vestn Oftalmol. 2000; 116(5):8-10. (In Russ.)

7. Boimer C., Birt C.M. Preservative Exposure and Surgical Outcomes in Glaucoma Patients: The PESO Study. J Glaucoma. 2013; 22(9) 730-735. doi.org/10.1097/ijg.0b013e31825af67d

8. Bely Yu.A., Tereshchenko A.V., Romanenko S.Ya., Nersesov Yu.E. Novikov S.V. The use of polymer elastic magnetic drainage at the stage of non-penetrating deep sclerectomy in open-angle glaucoma surgery Glaucoma. 2004; 2:38-45. (In Russ.)

9. Volik A.A., Naumenko V.V., Volik E.I. Experience of implantation of leucosapphire explant drainage in patients with refractory glaucoma. Innovative ophthalmology: Collection of scientific papers. Anapa; 2010: 82-83. (In Russ.)

10. Nikolaenko V.P., Astakhov S.Yu. The use of polytetrafluoroethylene explant drainages during hypotensive operations. Part II: complications. Glaucoma. 2005; 3:37-42. (In Russ.)

11. Chuprov A.D., Podyninogina V.V., Gavrilova I.A. Results of surgical treatment of advanced and terminal glaucoma using silicone drainage. Glaucoma. 2006; 3:26-29. (In Russ.)

12. Bolgov P.Ya. On Chiazzaro's operations for glaucoma. Vestn Oftalmol. 1945; 24(1-2):77-83. (In Russ.)

13. Kasparov A.A., Malozhen S.A., Trufanov S.V. The use of the amniotic membrane in the surgical treatment of glaucoma. Jubilee All-Russian Scientific and Practical Conference: Materials. Moscow, 2000. Part 1 134-136. (In Russ.)
More intense local reaction in the surgery site in $16(8.2 \%)$ patients was regarded as an allergic component. Local and systemic administration of anti-allergic drugs proved effective.

\section{Conclusions}

1. Composite drainage made of polylactic acid (polylactide) and polyethylene glycol (Glautex) is an effective and safe solution to the issue of surgical treatment of glaucoma. The indications for the use of this drainage implant are broad: primary open-angle and angle-closure glaucoma; secondary neovascular, uveitic, posttraumatic glaucoma.

2. The antihypertensive effectiveness of the Glautex drainage implant depends on the severity of the glaucomatous process and the timeliness of surgical intervention. The best outcomes are observed in primary open-angle glaucoma $(59.2 \%$ - absolute and $85.8 \%$ relative effectiveness).

3. The frequency and nature of complications depends on the degree of refractoriness of glaucoma, initial clinical characteristics of the process, and patients' multimorbidity. The most common complication is ciliochoroidal detachment (16.3\%).

4. Based on the results of this study, the Glautex drainage can be recommended for wider use in glaucoma surgery, including initial intervention.

14. Kurysheva N.I., Marnykh S.A., Kizeev M.V., Borzenok S.A., Bochkarev M.V., Fedorov A.A., Dolgina E.N. Intrascleral implantation of the amnion in the prevention of excessive scarring after antiglaucomatous operations (clinical and morphological study). Glaucoma. 2005; 1:29-36. (In Russ.)

15. Neroev V.V, Bykov V.P., Kvasha O.I, Belevtseva T.A. Surgical treatment of glaucoma by microdrainage. Clin Ophthalmol. 2009; 17(3):43-28. (In Russ.)

16. Popov M.Z. Observations on the operation of anterior chamber fistulization with live drainage. Russ Ophthalmol Zhurn. 1931; 14(6): 440-441. (In Russ.)

17. Anisimova S.Yu. Functional outcomes and hypotensive effect of nonpenetrating deep sclerlimbectomy with the use of collagen drainage resistant to biodegradation in the operation area. Glaucoma. 2005 ; 2:36-41. (In Russ.)

18. Anisimova S.Yu., Anisimov S.I., Rogacheva I.V. Surgical treatment of refractory glaucoma using a new collagen drainage resistant to biodegradation. Glaucoma. 2006; 2:51-56. (In Russ.)

19. Anisimova S.Yu., Anisimov S.I., Rogacheva I.V., Panasyuk A.F., Larionov E.V. New non-absorbable collagen drainage to improve the efficiency of non-penetrating deep sclerlimbectomy. Glaucoma. 2003; 1:19-23. (In Russ.)

20. Hsu W.C., Ritch R., Krupin T., Chen H.S. Tissue bioengineering for surgical bleb defects: an animal study. Graefes Arch Clin Exp Ophthalmol. 2008; 246(5):709-717. doi.org/10.1007/s00417-007-0744-9

21. Papaconstantinou D., Georgalas .I, Karmiris E., Diagourtas A., Koutsandrea C., Ladas I., Apostolopoulos M., Georgopoulos G. Trabeculectomy with OloGen versus trabeculectomy for the treatment of glaucoma: a pilot study. Acta Ophthalmol. 2010; 88(1):80-85.https://doi. org/10.1111/j.1755-3768.2009.01753.x

22. Aptel F., Dumas S., Denis P. Ultrasound biomicroscopy and optical coherence tomography imaging of filtering blebs after deep sclerectomy with new collagen implant. Eur J Ophthalmol. 2009; 19(2):223230. https://doi.org/10.1177/112067210901900208

23. Erichev V.P., Asratyan G.K. Surgical prevention of conjunctival-scleral scarring during antiglaucoma operations. Interregional scientific and practical conference of ophthalmologists, dedicated to the 80th anniversary of the Department of Eye Diseases of the Nizhny Novgorod State Medical Academy. 2012: 43-47. (In Russ.)

24. Erichev V.P., Ambartsumyan K.G., Fedorov A.A. Clinical and morphological evidence of the effect of preservatives on the surface of the eye in primary open-angle glaucoma. National J Glaucoma. 2014; 4(13):13-22. (In Russ.) 